\title{
BACTERIAS HETERÓTROFAS Y OLIGOTRÓFICAS EN ZONAS CONSERVADAS E INTERVENIDAS DEL PÁRAMO DE LA CORTADERA, BOYACÁ, COLOMBIA
}

\section{HETEROTROPHIC AND OLIGOTROPHIC BACTERIA IN PRESERVED AND INTERVENED AREAS OF THE PARAMO THE CORTADERA, BOYACÁ, COLOMBIA}

\author{
David Ricardo Hernández ${ }^{1}$, Luz Marina Lizarazo ${ }^{2}$ \\ ${ }^{1}$ Biólogo. Universidad Pedagógica y Tecnológica de Colombia, Joven Investigador Grupo de Investigación Biología Ambien- \\ tal, Escuela de Ciencias Biológicas, Avenida Central del Norte, Tunja, Boyacá, e-mail: davidhvel@gmail.com; ${ }^{2}$ Bacterióloga, \\ M.Sc. Ph.D. Universidad Pedagógica y Tecnológica de Colombia, e-mail: bio.ambient@uptc.edu.co
}

Rev. U.D.C.A Act. \& Div. Cient. 18(2): 475-483, Julio-Diciembre, 2015

RESUMEN

Los páramos brindan servicios ambientales fundamentales a la población, por la continua provisión de agua, en cantidad y en calidad y el almacenamiento de carbono atmosférico, que ayuda a regular el calentamiento global. Estos ecosistemas están sufriendo irreparables transformaciones, que controlan directa o indirectamente la estructura de las comunidades de microorganismos, cuya actividad es esencial para el mantenimiento de los ciclos biogeoquímicos. Se evaluó la diversidad de bacterias heterótrofas y oligotróficas, en los horizontes $\mathrm{A}, \mathrm{AB}$ y $\mathrm{B}$, de zonas conservadas y de zonas intervenidas en el Páramo de la Cortadera, en tres áreas de muestreo, ubicadas en los municipios de Siachoque, Pesca y Toca. El número de bacterias heterótrofas aeróbicas totales y bacterias oligotróficas, se estimaron como unidades formadoras de colonias, sembrándose en Agar TSA + Nistatina y Agar MSC-MSH, a $30^{\circ} \mathrm{C}$, por 48 horas. Los suelos tienen una textura franco arcilloso, con $\mathrm{pH}$ ácido, bajo contenido de materia orgánica y altos niveles de $\mathrm{P}$, aislándose los géneros Pseudomonas, Acinetobacter, Lactobacillus, Bacillus y Klebsiella, y bacterias oligotróficas de los géneros Caulobacter y Hyphomicrobium, siendo Pesca la zona más diversa del Páramo de La Cortadera. Dicha diversidad podría estar influenciada por una amplia gama de factores bióticos y abióticos, que se puede ver afectada por cambios ambientales o alteraciones antrópicas.

Palabras clave: Diversidad, cultivos, antrópico, horizontes, suelos.

\section{SUMMARY}

The "paramo" provides essential environmental services to the population, being an ecological unit that regulates the water flows, and atmospheric carbon storage, which helps to control global warming. These ecosystems are suffering irreparable transformations that directly or indirectly control the structure of communities of microorganisms, which activity is essential for the maintenance of biogeochemical cycles. The diversity of heterotrophic and oligotrophic bacteria in horizons A, $\mathrm{AB}$ and $\mathrm{B}$, of areas conserved and altered in the Páramo of Cortadera in the municipalities of Siachoque, Pesca and Toca were evaluated. The total number of aerobic heterotrophic and oligotrophic bacteria was estimated as colony forming units, being cultivated on Agar + Nystatin TSA Trypticase Soya Agar Scharlau ${ }^{\circledR}$ and Agar Agar MSC and $\mathrm{MSH}$ at $30^{\circ} \mathrm{C}$ for 48 hours respectively. The soils have a loamy clay texture, acid $\mathrm{pH}$, low organic matter and high levels of $\mathrm{P}$, isolating the genera Pseudomonas, Acinetobacter, Lactobacillus, Bacillus and Klebsiella, and oligotrophic bacteria genera Caulobacter, and Hyphomicrobium, being the most diverse the area Pesca. This diversity could be influenced by a wide range of biotic and abiotic factors, which can be affected by environmental changes and anthropogenic disturbances.

Key words: Diversity, crops, anthropic, horizonts, soils.

\section{INTRODUCCIÓN}

Los páramos, se encuentran entre los 3.200 y $4.500 \mathrm{~m}$ en las cadenas montañosas de los andes de Colombia, de Venezuela, de Ecuador, al norte de Perú, de Costa Rica y de 
Panamá. Estos ecosistemas son de gran importancia para el almacenamiento y la regulación hídrica, contribuyendo en la fijación de carbono, debido a la lenta descomposición de la materia orgánica y a los procesos de humificación, propios de los suelos (Daza-Torres et al. 2014).

En Colombia, estos ecosistemas presentan una extensión aproximada de 1.925.410 hectáreas, de las cuales, el 38,7\% se encuentran en áreas de Parques Nacionales Naturales (Rivera \& Rodríguez, 2011). A pesar de su notable significación, desde hace décadas están sufriendo enormes transformaciones, por la expansión humana y sus actividades, tales como la agricultura, la ganadería y, en algunos casos, la minería (Cañón-Cortázar et al. 2012).

Las prácticas agrícolas, el uso de fertilizantes y los sistemas de cultivo son factores que controlan directa o indirectamente la estructura de las comunidades de microorganismos del suelo. Parámetros, como la biomasa microbiana, su actividad metabólica y el conteo de las poblaciones microbianas más importantes de la microbiota del suelo, son indicadores fundamentales de la calidad del suelo, siendo la biomasa microbiana, un indicador que mejor refleja las respuestas al cambio ambiental, incluso, mejor que los parámetros físicos y químicos; no obstante, es difícil establecer indicadores de calidad, que permitan estimar y cuantificar su nivel de eficacia, porque muchos cambios ocurren paulatinamente y, por lo tanto, las variaciones en la calidad del suelo se perciben cuando todos los efectos se combinan, al cabo de determinado tiempo (Falkowski et al. 2008; Cañón-Cortázar et al. 2012).

En cuanto a la utilización de los nutrientes, las bacterias del suelo pueden ser clasificadas en oligotróficas y en copiotróficas. Las primeras, necesitan de una pequeña concentración de nutrientes, empleando lentamente la materia orgánica; las bacterias copiotróficas, por el contrario, necesitan una gran concentración de nutrientes, adaptándose a intervalos de latencia y de rápido crecimiento, dependiendo de la disponibilidad de estos sustratos (Saito et al.1998; Brenner et al. 2005); sin embargo, son muy pocos los estudios que se han desarrollado para conocer las poblaciones de bacterias oligotróficas presentes en suelos, ya que la mayoría de las investigaciones -referentes a estas bacterias-, se han llevado a cabo en ambientes marinos, agua dulce, suelos, materiales clínicos y agua ultra pura (Cho \& Giovannoni, 2004).

El Páramo de La Cortadera, se ubica dentro del complejo de páramos Tota - Bijagual -Mamapacha, presentando zonas secas, en el sector de Toca y Pesca y húmedas, en el municipio de Siachoque. Este complejo de páramos es uno de los que posee mayor actividad antrópica en el departamento de Boyacá (Morales et al. 2007), lo cual, ha incrementado el interés en realizar estudios microbiológicos edáficos, como un indicador sensible de la calidad del suelo, para evidenciar posibles relaciones entre la diversidad microbiana, edafología del suelo y la sustentabilidad del ecosistema.

En este contexto, se realizó este estudio de bacterias heterótrofas y oligotróficas del suelo en el Páramo de La Cortadera, que tiene como objetivo, evaluar la diversidad de bacterias edáficas cultivables en los suelos de las zonas conservadas e intervenidas del Páramo de la Cortadera, Boyacá, Colombia.

\section{MATERIALES Y MÉTODOS}

Área objeto de estudio. El estudio, se realizó en el Páramo de La Cortadera, entre febrero y noviembre de 2014. Se seleccionaron tres áreas de muestreo: Siachoque $\left(5^{\circ} 29^{\prime} 24,7^{\prime \prime} \mathrm{N}\right.$ y

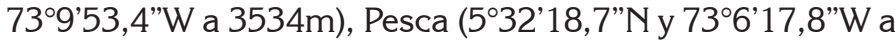
$3633 \mathrm{~m})$ y Toca $\left(5^{\circ} 34^{\prime} 52,9 \mathrm{~N}\right.$ y $73^{\circ} 7^{\prime} 23,2^{\prime \prime} \mathrm{W}$ a $\left.3208 \mathrm{~m}\right)$, localidades con promedios de precipitación mensual de $35,7 \mathrm{~mm}$ (Morales et al. 2007).

Se determinaron áreas con vegetación nativa de páramo, denominada Zonas Conservadas (ZC) y áreas de barbecho, con un descanso de, aproximadamente dos años, para Pesca y Toca y, de alrededor de 60 años, para Siachoque, denominada Zonas Intervenidas (ZI), constituyendo el cultivo de papa (Solanum tuberosum L), el predominante en estas áreas. Para ello, se tuvo en cuenta el estudio general de suelos y de zonificación de tierras del departamento de Boyacá, del Instituto Geográfico Agustín Codazzi (2005), cartografía básica y fotografías aéreas.

En estas zonas, se efectuaron seis calicatas de $1 \mathrm{~m}^{3} \mathrm{y}$, en cada una, se identificaron tres horizontes ( $\mathrm{A}, \mathrm{AB}$ y $\mathrm{B}$ ); el horizonte $\mathrm{A}$, se ubicó entre los $0-60 \mathrm{~cm}$, hasta evidenciar la desaparición de las raíces en la parte orgánica de la calicata; el horizonte $\mathrm{AB}$ fue la transición entre la parte orgánica y la arcillosa, entre los $60-80 \mathrm{~cm}$ y el horizonte $\mathrm{B}$ fue entre los 80 $100 \mathrm{~cm}$ en el fondo de la calicata, donde predominaban las arcillas, las areniscas y las rocas.

Toma de muestras. Se tomaron submuestras para cada uno de los horizontes $\mathrm{A}, \mathrm{AB}$ y $\mathrm{B}$, hasta completar cerca de $1 \mathrm{~kg}$ de suelo, para un total de 36, por zonas en estudio, se guardaron en bolsas Ziploc y se llevaron al laboratorio en neveras portables, tamizándolas a $2 \mathrm{~mm}$ y refrigerándolas, para su posterior análisis.

Análisis agroquímico del suelos. Se realizó en el Laboratorio Nacional de Suelos del Instituto Geográfico Agustín Codazzi. Se determinó $\mathrm{pH}$, por el método potenciométrico, en agua o en NaF; textura, por el método de Bouyoucos; CIC, por el método Acetato de amonio $1 \mathrm{~N}$ pH neutro y cuantificación, por volumetría y absorción-emisión atómica; conductividad eléctrica CE- Conductivimetría, en extracto de saturación; 
porcentaje de materia orgánica, por el método Calcinación a $540^{\circ} \mathrm{C}$ y cuantificación gravimétrica y elementos mayores y menores, por el método de extracción, con DTPA y cuantificación por Absorción Atómica A.A.

Cuantificación y clasificación de bacterias. Se pesaron $10 \mathrm{~g}$ por muestra de suelo, para realizar diluciones en serie, desde $10^{-1}$ hasta $10^{-4}$, usando agua destilada estéril.

Para el aislamientos de bacterias heterótrofas, se empleó el agar TSA + Nistatina Agar Tripticasa Soya- Scharlau ${ }^{\circledR}$ y los medios de cultivo agar MSC Mineral salts Caulobacter y MSH Mineral salts Hyphomicrobium, para el aislamiento de bacterias oligotróficas, de los géneros Caulobacter e Hyphomicrobium. Todos los medios de cultivo se sembraron por duplicado e incubaron a $30^{\circ} \mathrm{C}$, por 48 horas.

El número de bacterias heterótrofas aeróbicas totales y oligotróficas, se estimaron como unidades formadoras de colonias por gramo de suelo (UFC $\mathrm{g}^{-1}$ ).

A los aislados bacterianos heterótrofos, se les realizaron pruebas micromorfológicas y culturales, en los medios selectivos Agar EMB Pronadisa ${ }^{\circledR}$, Agar McConkey Pronadisa ${ }^{\circledR}$ y Agar Baird Parker Pronadisa ${ }^{\circledR}$. Se realizaron pruebas fisiológicobioquímicas utilizando API 20E, para enterobacterias-Biomérieux $^{\circledR}$; API $20 \mathrm{NE}$, para no enterobacterias-Biomérieux ${ }^{\circledR}$ y BBL Crystal ${ }^{\circledR}$, para Bacilos Gram positivos. En cuanto a las bacterias oligotróficas, se efectuaron pruebas bioquímicas tradicionales para los géneros Caulobacter e Hyphomicrobium, empleando el Manual de Bergey (Brenner et al. 2005).

Procesamiento de resultados. Se calculó el índice de diversidad de Shannon, en los suelos de las zonas estudiadas; para el cálculo de este índice, se consideró la siguiente fórmula:

$$
\mathrm{H}^{\prime}=-\Sigma \text { piLn(pi), donde } \mathrm{pi}=\mathrm{ni} / \mathrm{N}
$$

Análisis estadísticos. Los datos de la cuantificación microbiana, se transformaron a Logaritmo en base 10, para que cumplieran con la distribución normal; con estos datos obtenidos, se realizó un análisis de varianza de tres factores; se aplicó la prueba de normalidad de Shapiro-Wilk y el análisis de varianza correspondiente, con un nivel de significación de 0,01 . Además, se practicó la prueba de comparación múltiple de Tukey, para determinar diferencias significativas de las variables evaluadas, entre los usos de los suelos estudiados. Se utilizó el paquete SigmaPlot 12.0.

\section{RESULTADOS Y DISCUSIÓN}

Análisis agroquímico de los suelos. El suelo de las tres áreas estudiadas, se caracterizó por presentar una textura franco arcillosa (FAr), tal como se ha informado para suelos cultiva- dos con papa (Flórez-Zapata \& Uribe-Vélez, 2011) y en suelos de páramo (Lizarazo-Medina \& Gómez-Vásquez, 2015). Además, los suelos de estas zonas presentaron un $\mathrm{pH}$ ácido ( $\mathrm{pH}: 4,3)$; este valor es similar a los reportados por Moratto et al. (2005) y Estupiñán et al. (2009), quienes informaron pH de 4,1 a 5,4, para el Páramo Guerrero y de 3,8, para el Páramo el Granizo, respectivamente. Asimismo, Lizarazo-Medina \& Gómez-Vásquez (2015), en los Páramos de Santa Inés y Frontino-Urrao, en el departamento de Antioquia, declararon $\mathrm{pH}$ de 4,33 y 4,31 , respectivamente.

Para el Páramo de la Cortadera, los valores de pH reportados en las ZC y ZI son ideales para el establecimiento de poblaciones microbianas, al ubicarse en el rango óptimo de $\mathrm{pH}$ 4-7, para el crecimiento bacteriano (Lauber et al. 2009; Rousk et al. 2010), siendo este un factor ambiental determinante de la diversidad y de la composición de las comunidades microbianas del suelo (Lauber et al. 2009; Siciliano et al. 2014); sin embargo, estas poblaciones se pueden ver afectadas por las prácticas agrícolas y por las condiciones climáticas, que podrían generar variaciones en el $\mathrm{pH}$ y en la disponibilidad de nutrientes (Figueiredo et al. 2015). Además, permite la adaptabilidad de especies vegetales (Estupiñán et al. 2009), ofreciendo una mayor disponibilidad y retención de elementos menores, como $\mathrm{Fe}, \mathrm{Mg}$, Cu y $\mathrm{Zn}$, que forman complejos estables con la materia orgánica, haciéndolos más solubles y, por lo tanto, más fáciles de absorber -haciéndolos más solubles-, lo que permite que sean más fáciles de absorber por las plantas; además, impide que se generen concentraciones de aluminio mayores a 1ppm, que llegan a ser tóxicas para las plantas (Instituto Geográfico Agustín Codazzi, 2005; Figueroa del Castillo et al. 2010).

Por otro lado, se registraron altos contenidos de materia orgánica para las calicatas conservadas, especialmente, en el área de Siachoque $(8,2 \%)$, en comparación a los obtenidos en las calicatas intervenidas, siendo las áreas de Pesca $(8,1 \%)$ y Siachoque $(7,2 \%)$, las que presentaron los valores más altos de esta zona. En la tabla 1, se muestran altas concentraciones de fósforo en los suelos de las calicatas intervenidas $(10,6-38,9 \mathrm{mg} / \mathrm{kg})$, con bajas concentraciones para las ZC (0,96-8,41 mg/kg). Moratto et al. (2005), en áreas cultivadas con papa (Solanum tuberosum L) y áreas en descanso, obtuvo valores de MO, entre 19-62\% y contenidos de fósforo, de $99,5 \mathrm{mg} / \mathrm{kg}$, siendo superiores a los hallados en este estudio; no obstante, en zonas de páramo, Lizarazo-Medina \& Gómez-Vásquez (2015) informaron concentraciones de $\mathrm{P}$, de $6,71-29,69 \mathrm{mg} / \mathrm{kg}$ y porcentajes de $\mathrm{MO}$, de $11,72 \%$ y $35,31 \%$, existiendo similitud con los resultados obtenidos en este estudio.

Estos valores de materia orgánica y altos contenidos de fósforo en las ZI, posiblemente, pueden están influenciados por cambios en las propiedades fisicoquímicas del suelo, por el 
Tabla 1. Análisis agroquímicos de suelos muestreados en las zonas conservadas (ZC) e intervenidas (ZI) del Páramo de la Cortadera.

\begin{tabular}{|c|c|c|c|c|c|c|c|}
\hline \multirow{3}{*}{ Análisis } & \multirow{3}{*}{ Unidad } & \multicolumn{6}{|c|}{ Zonas de Muestreo } \\
\hline & & \multicolumn{2}{|c|}{ Siachoque } & \multicolumn{2}{|c|}{ Pesca } & \multicolumn{2}{|c|}{ Toca } \\
\hline & & $\mathrm{ZC}$ & ZI & $\mathrm{ZC}$ & ZI & $\mathrm{ZC}$ & ZI \\
\hline Textura & & $\mathrm{FAr}$ & FAr & FAr & FAr & $\mathrm{FAr}$ & FAr \\
\hline $\mathrm{pH}$ & & 3,96 & 3,96 & 4,26 & 4,66 & 4,56 & 4,66 \\
\hline Aluminio (Al) & $\mathrm{cmol}(+) / \mathrm{kg}$ & 13,78 & 13,04 & 10,91 & 5,42 & 4,08 & 3,81 \\
\hline Saturación Al & $\%$ & 96,34 & 96,04 & 95,50 & 74,27 & 92,81 & 83,19 \\
\hline $\mathrm{MO}$ & $\%$ & 8,22 & 8,16 & 4,84 & 7,24 & 3,37 & 2,97 \\
\hline $\mathrm{CIC}$ & $(\mathrm{cmol}(+) / \mathrm{kg})$ & 39,33 & 37,14 & 30,64 & 35,56 & 23,60 & 20,86 \\
\hline Calcio & $(\mathrm{cmol}(+) / \mathrm{kg})$ & 0,07 & 0,13 & 0,12 & 0,78 & 0,09 & 0,58 \\
\hline Magnesio & $(\mathrm{cmol}(+) / \mathrm{kg})$ & 0,10 & 0,11 & 0,21 & 0,10 & 0,05 & 0,11 \\
\hline Potasio & $(\mathrm{cmol}(+) / \mathrm{kg})$ & 0,29 & 0,25 & 0,29 & 0,27 & 0,13 & 0,20 \\
\hline Sodio & $(\mathrm{cmol}(+) / \mathrm{kg})$ & 0,09 & 0,06 & 0,06 & 0,05 & 0,07 & 0,04 \\
\hline B.T. & $(\mathrm{cmol}(+) / \mathrm{kg})$ & 0,55 & 0,55 & 0,54 & 1,22 & 0,34 & 0,94 \\
\hline S.B. & $\%$ & 1,60 & 1,62 & 1,74 & 2,93 & 1,46 & 3,84 \\
\hline Fósforo & $\mathrm{mg} / \mathrm{kg}$ & 8,41 & 10,66 & 0,96 & 38,98 & 1,10 & 34,82 \\
\hline
\end{tabular}

FAr: Franco Arcilloso; MO: Materia orgánica; CIC: Capacidad de Intercambio Catiónico; B.T: Bases totales; S.B: Saturación de Bases.

ingreso de nuevas poblaciones de microorganismos, por disturbios de origen antrópico o natural, variaciones en las condiciones ambientales o aplicación de fertilizantes, tal como se pudo evidenciar en las áreas de Pesca y Toca. Además, un mayor contenido de fósforo es el reflejo de la adecuación de los suelos, para los procesos productivos (Drenovsky et al. 2004); sin embargo, los valores bajos de fósforo que se observaron en las ZC, se deben a los procesos de retención del ecosistema, en los que intervienen los compuestos de hierro y de aluminio y la fauna del suelo, que favorecen los procesos de humificación (Drenovsky et al. 2004; Estupiñán et al. 2009).

Análisis microbiológico. Se registraron concentraciones de

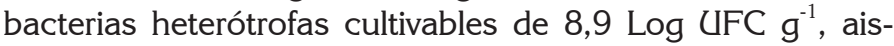
lándose 11 géneros bacterianos, con mayor abundancia de microorganismos en las ZC $(51,1 \%)$. El horizonte A es el de mayor concentración microbiana, mientras que los horizontes $\mathrm{AB}$ y $\mathrm{B}$ registraron los más bajos valores, evidenciándose que existen diferencias significativas $(P=<0,001)$, entre la abundancia de microorganismos y los horizontes del suelo en las ZC y ZI estudiadas (Figura 1). Beltrán-Pineda (2014), en suelos cultivados con papa en el Páramo de Rabanal, reportó recuentos de 3,7 Log de UFC $\mathrm{g}^{-1}$; sin embargo, en suelos de este mismo páramo que han sufrido quemas, se registran poblaciones de bacterias amilolíticas, proteolíticas y celulolíticas, de 4,8, 4,6 y 4,3 Log UFC ${ }^{-1}$, respectivamente (Beltrán-Pineda \& Lizarazo-Forero, 2013). Igualmente, Lizarazo-Medina \& Gómez-Vásquez (2015), en la rizosfera de Espeletia spp., en páramos de Antioquia, reportan una abundancia de microorganismos de $2,51 \times 10^{5}$ UFC g- $^{1}$ y
$2,24 \times 10^{5} \mathrm{UFC}^{-1}$, pero estos estudios se limitan, principalmente, a los $20 \mathrm{~cm}$ superiores del suelo. Como resultado, las comunidades microbianas que existen a diferentes profundidades del suelo no han sido bien caracterizadas (Eilers et al. 2012); no obstante, como lo reportado en este estudio, la abundancia y la diversidad microbiana disminuye con la profundidad (Buss et al. 2005), representando un filtro ecológico, ya que muchos microorganismos que habitan en la superficie tienen menos probabilidades de prosperar en el entorno de los horizontes más profundos del suelo (Eilers et al. 2012).

Por tal razón, estos valores de ocurrencia de microorganismos podrían estar relacionados con la proporción de materia orgánica en las ZC y la humedad característica de estos suelos. Ramos \& Zúñiga (2008) señalaron que un alto porcentaje de humedad favorece la actividad de los microorganismos, permitiéndoles reaccionar fácil y rápidamente a estímulos ambientales; sin embargo, en las ZI, esta actividad microbiana, se puede ver afectada por la aplicación intensiva de agroquímicos y, en parte, por el tipo de labranza, lo que genera un cambio drástico en la estructura del suelo y en las poblaciones de microorganismos, disminuyendo así su concentración y su biodiversidad (Rengel \& Marschner, 2005).

Microrganismos aislados. En ambos ecosistemas estudiados, Pseudomonas se destacó como el género más abundante (86,1\%), seguido de los géneros Acinetobacter $(3,2 \%)$, Lactobacillus $(1,9 \%)$, Bacillus $(1,6 \%)$ y Klebsiella(1,6\%), mientras que Corynebacterium, con $0,06 \%$, solo fue aislado en las ZI (Tabla 2). Las bacterias pertenecientes al género Pseu- 

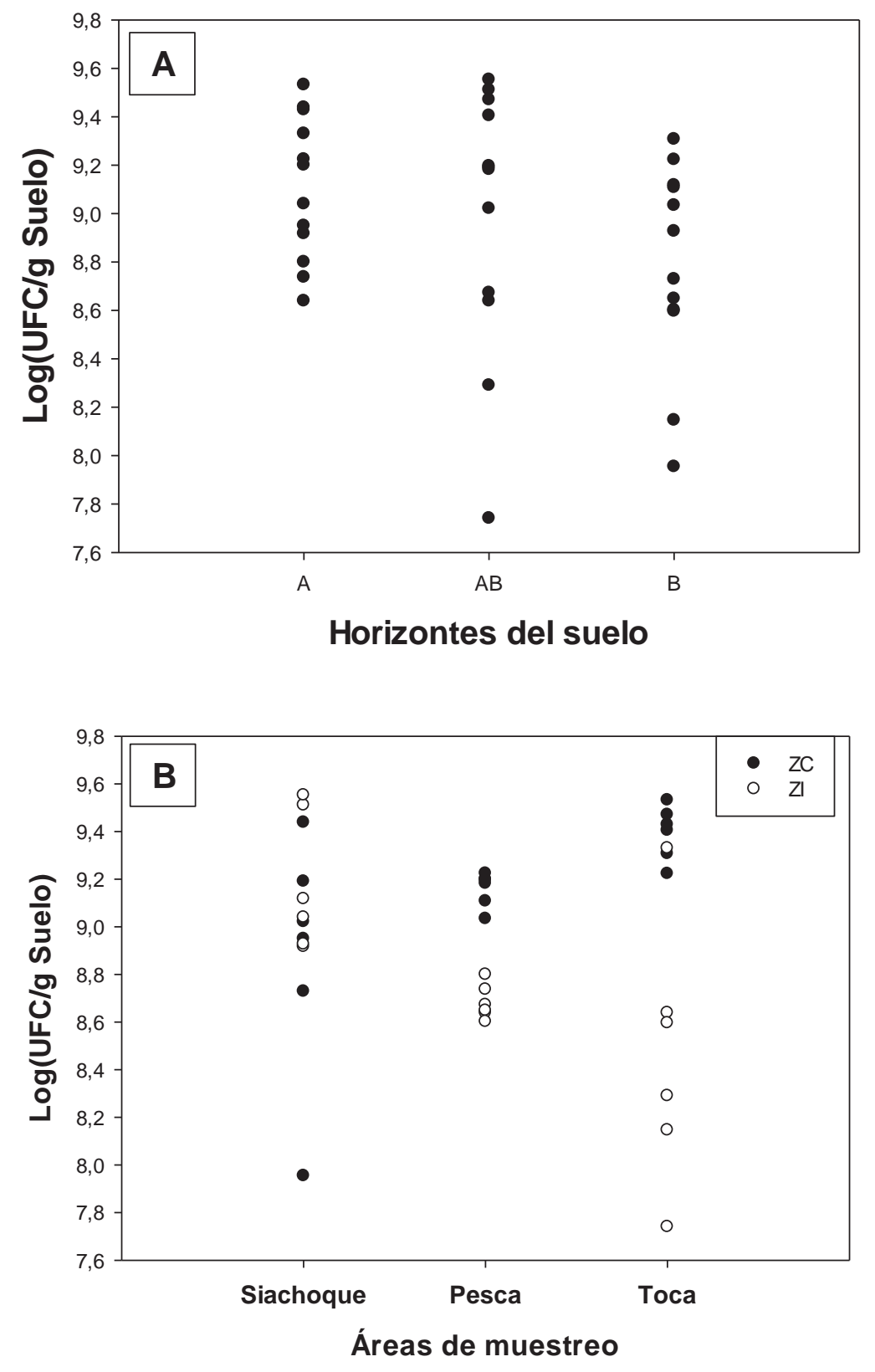

Figura 1. Concentraciones microbianas presentes en el Páramo de la Cortadera. A. Horizontes del suelo (A, AB, B), B. Áreas de muestreo, Zonas conservadas (ZC) e intervenidas (ZI).

domonas presentan características que le permite adaptarse con facilidad en diferentes agroecosistemas, destacándose por su corto período de latencia, rápida velocidad de crecimiento y capacidad de metabolizar una amplia gama de sustancias carbonadas, exudadas por las raíces de las plantas (Hernández-Rodríguez et al. 2003); por ejemplo, se ha aisla- do en suelos bajo cultivos de papa (S. tuberosum) (Moratto et al. 2005) y de la rizósfera de Espeletia spp., (Lizarazo-Medina \& Gómez-Vásquez 2015), demostrando su capacidad para descomponer la materia orgánica, haciendo disponible el fósforo y produciendo compuestos que promueven el crecimiento de las plantas (Chakraborty et al. 2010; Muleta et 
al. 2013). Los géneros aislados en este estudio forman parte de los Phylum Actinobacteria, Firmicutes y Proteobacteria, siendo Pseudomonas y Bacillus, los representantes más comunes en muestras de suelo de alta montaña (Lyngwi et al. 2013); sin embargo, los resultados muestran una baja abundancia del género Bacillus, comportamiento que podría estar relacionado con el alto contenido de nutrientes, presentes en los suelos del Páramo de la Cortadera.

En relación con el género Acinetobacter, se ha documenta-

Tabla 2. Porcentaje de aislamiento de los géneros bacterianos presentes en el Páramo de la Cortadera.

\begin{tabular}{|c|c|}
\hline Géneros bacterianos aislados & \% Aislamiento \\
\hline \multicolumn{2}{|c|}{ Heterótrofas } \\
\hline Pseudomona & 86,17 \\
\hline Acinetobacter & 3,29 \\
\hline Lactobacillus & 1,95 \\
\hline Bacillus & 1,66 \\
\hline Klebsiella & 1,6 \\
\hline Staphilococcus & 0,93 \\
\hline Burkholderia & 0,92 \\
\hline Amphibacillus & 0,42 \\
\hline Enterobacter & 0,13 \\
\hline Corynebacterium & 0,06 \\
\hline Micrococcus & 0,01 \\
\hline Oligotróficas \\
\hline Caulobacter & 2,12 \\
\hline Hyphomicrobium & 0,74 \\
\hline
\end{tabular}

do, en los últimos años, su gran capacidad metabólica, que le permite catabolizar una amplia variedad de compuestos naturales, lo que implica su participación activa en el ciclo de los nutrientes en los ecosistemas. Además, se ha demostrado su presencia abundante en diversos ambientes, que incluyen el suelo, los ecosistemas acuáticos y ambientes impactados (Baumann, 1968; Kostka et al. 2011; Jung \&Park, 2015). En un estudio realizado por Sturz et al. (2001), se corroboró la importancia de Acinetobacter y su especificidad con las especies vegetales, demostrándose sus potencialidades en la estimulación del crecimiento y del desarrollo de la papa cultivar Russet Burbank.

Bacterias oligotróficas. Se aislaron concentraciones de 1,8 Log UFC $\mathrm{g}^{-1}$ de este grupo de bacterias, representadas en dos géneros: el Caulobacter, con un 2,1\%, muestra un alto nivel de aislamiento, principalmente, para las zonas conservadas y los horizontes $\mathrm{AB}$ y $\mathrm{B}$ de las áreas estudiadas, mientras que el género Hyphomicrobium, con 0,7\%, se aisló en menor proporción (Tabla 2). Saito et al. (1998) afirmaron que estos microorganismos se hallan ampliamente distribuidos en el suelo, desempeñando un papel importante en la descomposición de la materia orgánica y dinámica de nutrientes del suelo (Hashimoto et al. 2006); no obstante, el bajo porcentaje de aislamiento de estos géneros, podría estar influenciado por las propiedades agroquímicas registradas en los suelos del Páramo de la Cortadera, si se tiene en cuenta lo planteado por Phung et al. (2004), quienes señalaron que estos microorganismos crecen mejor a concentraciones de nutrientes menores a $10 \mathrm{mg}$.

Análisis de diversidad. Los ecosistemas pertenecientes a las Zonas intervenidas de Pesca y Siachoque y la Zona Conservada de Toca, se caracterizan por tener la mayor diversidad del páramo de la Cortadera (Figura 2). Esta biodiversidad podría ser favorecida por la presencia de cultivos que vienen acompañados de nuevos sustratos, como la cáscara de arroz y de gallinaza, que favorecen la presencia y la abundancia de mayor cantidad de grupos microbianos (Vallejo-Quinter, 2013), pero esta diversidad se podría ver afectada por los usos agrícolas de los suelos, disminuyendo el ingreso de nutrientes al suelo y, consecuentemente, pérdida del contenido de carbono orgánico y nitrógeno.

Este estudio es de gran importancia para el departamento de Boyacá, ya que se da a conocer, por primera vez, la diversidad bacteriana asociada a zonas conservadas e intervenidas, ubicadas en el Páramo de la Cortadera. Las concentraciones bacterianas reportadas en este estudio hacen referencia a la fracción cultivable de algunos géneros microbianos, siendo indispensable aplicar nuevas metodologías de cultivo, que permitan conocer la diversidad microbiana total en estos ecosistemas, poco estudiados. Los resultados muestran que los microorganismos aislados tienen la capacidad de dinamizar la materia orgánica y fósforo presente en estos suelos, favoreciendo al sustento de los flujos de energía, la dinámica de los nutrientes, la estructura del suelo y la biodiversidad en estos ecosistemas de alto impacto, en el almacenamiento y en la regulación hídrica.

Agradecimientos: Los autores agradecen a Colciencias, a la Dirección de Investigaciones de la Universidad Pedagógica y Tecnológica de Colombia, al Ph.D. José Luis Machado, por el apoyo en el análisis de datos. Conflicto de interés: El manuscrito fue preparado y revisado con la participación de todos los autores, quienes declaramos que no existe ningún tipo de conflicto de interés que ponga en riesgo la validez de los resultados presentados. 


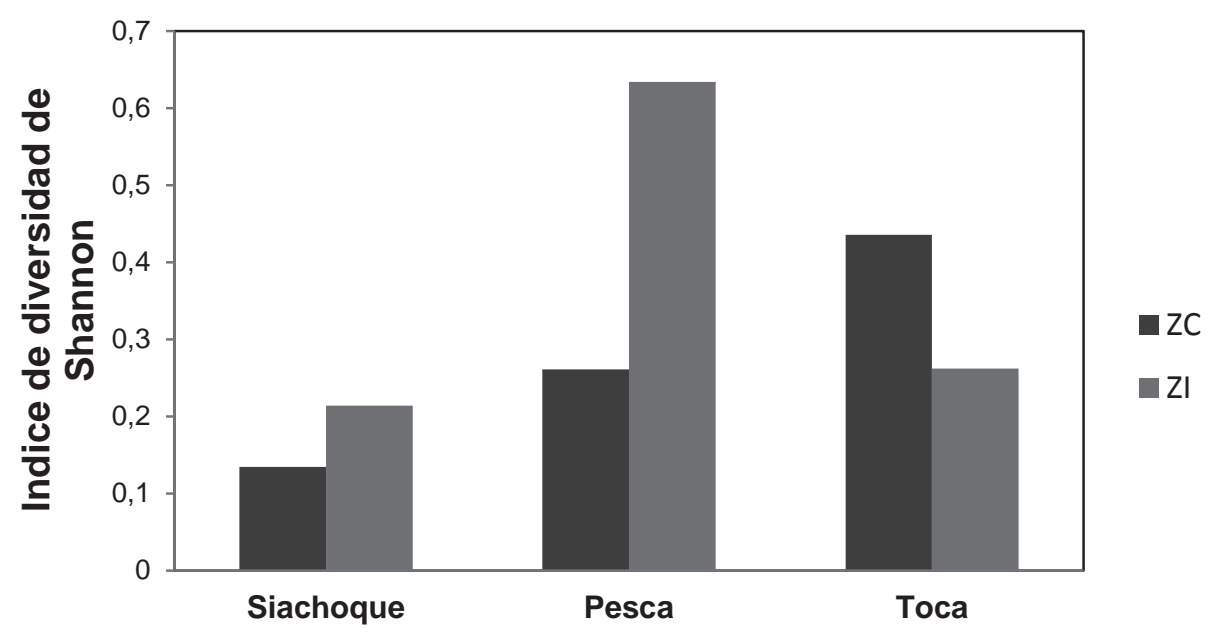

Zonas de muestreo - Parcelas

Figura 2. Índice de diversidad de Shannon en las zonas conservadas (ZC) e intervenidas (ZI) del Páramo de la Cortadera.

\section{BIBLIOGRAFÍA}

1. BAUMANN, P. 1968. Isolation of Acinetobacter from Soil and Water.Journal of Bacteriology. 96(1):39-42.

2. BELTRÁN-PINEDA, M.; LIZARAZO-FORERO, L.M. 2013. Grupos funcionales de microorganismos en suelos de páramo perturbados por incendios forestales. Rev. Ciencias. 17(2):121-136.

3. BELTRÁN-PINEDA, M. 2014. Estudio comparativo de poblaciones microbianas totales y solubilizadoras de fosfato en suelos de páramo cultivados con papa (Solanumtuberosum) en Ventaquemada-Boyacá. I3+ Investigación, Innovación, Ingeniería. 2:56-74.

4. BRENNER, D.; KRIEG, N.; JAMES, T. 2005. Bergey's Manual of Systematic Bacteriology. Volume 2: The Proteobacteria (Part C). 2 Ed. Springer. ISBN-10: 0-387-24145-0. ISBN-13: 978-0387-24145-6.

5. BUSS, H.; BRUNS, M.; SCHULTZ, M.; MOORE, J.; MATHUR, C.; BRANTLEY, S. 2005. The coupling of biological iron cycling and mineral weathering during saprolite formation, Luquillo Mountains, Puerto Rico. Geobiology. 3:247-260.

6. CAÑÓN-CORTÁZAR, R.; AVELLANEDA-TORRES, L.; TORRES-ROJAS, E. 2012. Microorganismos asociados al ciclo del nitrógeno en suelos bajo tres sistemas de uso: cultivo de papa, ganadería y páramo, en el Parque Los Nevados, Colombia. Acta Agr. 61(4):371-379.

7. CHAKRABORTY, B.; CHAKRABORTY, U.; SHA, A.; SUNAR, K.; DEY, P. 2010. Evaluation of phosphate solubilizers from soils of North Bengal and their diversity analysis. World J. Agr. Sci. 6(2):195-200.

8. CHO, J.; GIOVANNONI, S. 2004. Cultivation and growth characteristics of a diverse group of oligotrophic marine Gammaproteobacteria. Appl. Environ. Microbiol. 70:432-440.

9. DAZA-TORRES, M.; HERNÁNDEZ-FLOREZ, F.; TRIANA, F. 2014. Efecto del uso del suelo en la capacidad de almacenamiento hídrico en el Páramo de Sumapaz Colombia. Rev. Fac. Nal. Agr. Medellin. 67(1):71897200 .

10. DRENOVSKY, R.; VO, D.; GRAHAM, K.; SCOW, K. 2004. Soil water content and organic carbon availability are major determinants of soil microbial community composition. Micro. Ecol. 48:424-430.

11. EILERS, K.; DEBENPORT, S.; ANDERSON, S.; FIERER, N. 2012. Digging deeper to find unique microbial communities: The strong effect of depth on the structure of bacterial and archaeal communities in soil. Soil Biol. Biochem. 50:58-65. 
12. ESTUPIÑÁN, L.; GÓMEZ, J.; BARRANTES, V.; LIMAS, L. 2009. Efecto de actividades agropecuarias en las características del suelo en el páramo el Granizo (Cundinamarca - Colombia). Rev. U.D.C.A Act. \& Div. Cient. 12(2):79-89.

13. FALKOWSKI, P.; FENCHEL, T.; DELONG, E. 2008. The microbial engines that drive Earth's biogeochemical cycles. Science. 320:1034-1039.

14. FIGUEIREDO, N.; CARRANCA, C.; GOUFO, P.; PEREIRA, J.; TRINDADE, H.; COUTINHO, J. 2015. Impact of agricultural practices, elevated temperature and atmospheric carbon dioxide concentration on nitrogen and $\mathrm{pH}$ dynamics in soil and floodwater during the seasonal rice growth in Portugal. Soil Tillage Res. 145:198-207.

15. FIGUEROA DEL CASTILLO, L.; MELGAREJO, M.; FUENTES DE PIEDRAHÍTA, C.; LOZANO DE YUNDA, A. 2010. Mineralización de 14C-glifosato y seguimiento de la dinámica de las poblaciones de Pseudomonas sp. en tres suelos del departamento del Tolima (Colombia) sometidos a diferente uso. Agron. Col. 28(3):413-420.

16. FLÓREZ-ZAPATA, N.; URIBE-VÉLEZ, D. 2011. Biological and physicochemical parameters related to the nitrogen cycle in the Rhizospheric soil of native potato (Solanum phureja) crops of Colombia. Appl. Environm. Soil Sci. Article ID 847940, 10p.

17. HASHIMOTO, T.; WHANG, S.K.; NAGAOKA, T. 2006. A quantitative evaluation and phylogenetic characterization of oligotrophic denitrifying bacteria harbored in subsurface upland soil using improved culturability. Biol. Fertil. Soils. 42:179-185.

18. HERNÁNDEZ-RODRÍGUEZ, A.; CABALLERO, A.; PAZOS, M.; RAMÍREZ, R.; HEYDRICH, M. 2003. Identificación de algunos géneros microbianos asociados al cultivo del maíz (Zea mays L.) en diferentes suelos de Cuba. Rev. Col. Biotecn. 5(1):45-55.

19. INSTITUTO GEOGRÁFICO AGUSTÍN CODAZZI. 2005. Estudio general de suelos y zonificación de tierras del departamento de Boyacá. Universidad Pedagógica y Tecnológica de Colombia. Tunja, Boyacá. 158p.

20. JUNG, J.; PARK, W. 2015. Acinetobacter species as model microorganisms in environmental microbiology: current state and perspectives. Appl. Microbiol. Biotechnol. 99(6):2533-2548.
21. KOSTKA, J.; PRAKASH, O.; OVERHOLT, W.; GREEN, S.; FREYER, G.; CANION, A.; DELGARDIO, J.; NORTON, N.; HAZEN, T.; HUETTEL, M. 2011. Hydrocarbon-degrading bacteria and the bacterial community response in gulf of Mexico beach sands impacted by the deepwater horizon oil spill. Appl. Environ. Microbiol. 77(22):7962-7974.

22. LAUBBER, C.; HAMADY, M.; KNIGHT, R.; FIERER, N. 2009. Pyrosequencing-based assessment of soil $\mathrm{pH}$ as a predictor of soil bacterial community structure at the continental scale. Appl. Environ. Microbiol. 75(15):5111-5120.

23. LIZARAZO-MEDINA, P.; GÓMEZ-VÁSQUEZ, D. 2015. Microbiota rizosférica de Espeletia spp. de los Páramos de Santa Inés y de Frontino-Urrao en Antioquia, Colombia. Acta Biol. Col. 20(1):175-182.

24. LYNGWI, N.; KOIJAM, K.; SHARMA, D.; JOSHI, R. 2013. Cultivable bacterial diversity along the altitudinal zonation and vegetation range of tropical Eastern Himalaya. Rev. Biol. Trop. 61(1):467-490.

25. MORALES, M.; OTERO, J.; VAN DER HAMMEN, T.; TORRES, A.; CADENA, C.; PEDRAZA, C. 2007. Atlas de páramos de Colombia. Instituto de Investigación de Recursos Biológicos Alexander Von Humboldt. 208p.

26. MORATTO, C.; MARTÍNEZ, L.; VALENCIA, H.; SÁNCHEZ, J. 2005. Efecto del uso del suelo sobre hongos solubilizadores de fosfato y bacterias diazotróficas en el páramo de Guerrero (Cundinamarca). Agr. Col. 23(2):299-309.

27. MULETA, D.; ASSEFA, F.; BÖRJESSOON, E.; GRANHALL, U. 2013. Phosphate solubilisingrhizobacteria associated with Coffeaarabica L. in natural coffee forests of southwestern Ethiopia. J. Saudi Soc. Agr. Sci. 12:73-84.

28. PHUNG, N.; LEE, J.; HYUN, K.; CHANG, I.; GADD, G.; HONG, B. 2004. Analysis of microbial diversity in oligotrophic microbial fuel cells using $16 \mathrm{~S}$ rDNA sequences. Microbiol. Letters. 233:77-82.

29. RAMOS, E.; ZÚÑIIGA, D. 2008. Efecto de la humedad, temperatura y $\mathrm{pH}$ del suelo en la actividad microbiana a nivel de laboratorio. Ecol. Apli. 7(1-2):123-130.

30. RENGEL, Z.; MARSCHNER, P. 2005. Nutrient availability and management in the Rhizosphere: exploiting genotypic differences. New Phytol. 168:305-312. 
31. RIVERA, D.; RODRÍGUEZ, C. 2011. Guía divulgativa de criterios para la delimitación de páramos de Colombia. Instituto Humboldt. 68p.

32. ROUSK, J.; BAATH, E.; BROOKES, P.; LAUBER, C.; LOZUPONE, C.; CAPORASO, G.; KNIGHT, R.; FIERER, N. 2010. Soil bacterial and fungal communities across a pH gradient in an arable soil. The ISME J. 4:1340-1351.

33. SAITO, A.; MITSUI, H.; HATTORI, R.; MINAMISAWA, K.; HATTORI, T. 1998. Slow-growing and oligotrophic soil bacteria philogenetically close to Bradyrhizobium japonicum. Microbiol. Ecol. 25(3):277-286.

34. SICILIANO, S.; PALMER, A.; WINSLEY, T.; LAMB, E.; BISSETT, A.; BROWN, M.; DORST, J.; JI, M.; FERRARI, B.; GROGAN, P.; CHU, H.; SNAPE, I. 2014. Soil fertility is associated with fungal and bacterial richness, whereas $\mathrm{pH}$ is associated with community composition in polar soil microbial communities. Soil Biol. Biochem. 78:10-20.

35. STURZ, A.; MATHESON, B.; ARSENAULT, W.; KIMPINSKI, J.; CHRISTIE, B. 2001. Weeds as a source of plant growth promoting rhizobacteria in agricultural soils. Can. J. Microbiol. 47(11):1013-1024.

36. VALLEJO-QUINTERO, V. 2013. Importancia y utilidad de la evaluación de la calidad de suelos mediante el componente microbiano: experiencias en sistemas silvopastoriles. Colombia Forestal. 16(1):83-99.

Recibido: Febrero 2 de 2015

Aceptado: Septiembre 20 de 2015

\section{Cómo citar:}

Hernández, D.R.; Lizarazo, L.M. 2015. Bacterias heterótrofas y oligotróficas en zonas conservadas e intervenidas del páramo de la Cortadera, Boyacá, Colombia. Rev. U.D.C.A Act. \& Div. Cient. 18(2): 475-483. 